\title{
Thermal stability and flammability of styrene-butadiene rubber (SBR) composites
}

\author{
Effect of attapulgite, silica, carbon nanofiber, and the synergism of their action on the \\ properties SBR composites
}

\author{
Przemysław Rybiński · Grażyna Janowska • \\ Małgorzata Jóźwiak • Marek Jóźwiak
}

Received: 1 October 2012/Accepted: 4 December 2012/Published online: 25 December 2012

(C) The Author(s) 2012. This article is published with open access at Springerlink.com

\begin{abstract}
The article presents the effect of attapulgite (ATT) and its synergic action with carbon or silica on the thermal properties and flammability of cross-linked styrene-butadiene rubber. It has been shown that ATT is active filler improving the thermal and mechanical properties of composites containing this aluminosilicate. The decreased flammability of vulcanizates containing ATT compared to that of unfilled vulcanizates results from good insulating properties of the ATT used. The considerable reduction in the flammability of composites containing ATT and carbon nanofiber or silica is connected, first of all, with the formation of a homogeneous boundary layer.
\end{abstract}

Keywords Styrene-butadiene rubber - Attapulgite . Carbon nanofibers · Thermal stability $\cdot$ Flammability

\section{Introduction}

Recent years have witnessed a great interest in polymeric materials with special properties, resistant to the action of considerably lowered or elevated temperature, flameretardant or non-flammable, being characterized by suitable mechanical strength at the same time.

In the making of polymeric materials with increased thermal stability and resistance to the action of fire, one uses various types of mineral fillers, such as calcium carbonate,

P. Rybiński ( $)$ · M. Jóźwiak · M. Jóźwiak

Management of Environment Protection and Modeling,

The Jan Kochanowski University, Kielce, Poland

e-mail: przemyslaw.rybinski@ujk.edu.pl

G. Janowska

Institute of Polymer and Dye Technology,

Technical University of Łódź, Lodz, Poland silica, halloysite, or montmorillonite [1-3]. From recent literature reports it follows that fibrous aluminosilicate (attapulgite, ATT) can also be active mineral filler [4].

ATT of chemical formula: $\mathrm{Mg}_{5}[\mathrm{Al}] \mathrm{Si}_{8} \mathrm{O}_{20}(\mathrm{OH})_{2}-\left(\mathrm{OH}_{2}\right)_{4} \times$ $4 \mathrm{H}_{2} \mathrm{O}$ is characterized by a high sorption capacity ranging from 15 to $30 \mathrm{mval} / 100 \mathrm{~g}$, showing features of a molecular sieve as zeolites $[5,6]$. ATT is widely used as absorbent, catalyst carrier, disinfectant, adhesive agent, food or drug additive as well as filler of polymers [4]. It has a three-level structure. Single fibrous crystals are the smallest structural unit with a length of 500-2,000 nm and a diameter of 10-30 nm. Each single crystal consists of many laminar units such as tetrahedrons comprising two silicon atoms and two oxygen atoms [7-9]. Between neighboring layers are five aluminum atoms tetrahedrally combined with five oxygen atoms. Individual structural units are combined with oxygen atoms to form a crystalline structure in the form of fiber. Particular fibrous nanocrystals are arranged in bundles that undergo agglomeration visible in a micro-scale as large solid particles [10].

This article presents the results of examining the effect of ATT and its modification procedure on the thermal stability and flammability of styrene-butadiene rubber (SBR) cross-linked by means of an organic peroxide or sulfur. A particular attention was paid to the structure of the rubber combustion residue. The effect of the synergic action of ATT and carbon nanofiber or silica on the properties of cross-linked SBR was also assessed.

\section{Experimental}

Materials

The object of our study was SBR, KER 1500 form Synthos, containing $23.5 \%$ of combined styrene. The rubber was 
cross-linked by means of dicumyl peroxide (DCP) in the presence of zinc oxide $(\mathrm{ZnO})$ or by means of sulfur in the presence of $\mathrm{ZnO}$ and $\mathrm{N}$-cyclohexyl-2-benzoylsulfenamide (Tioheksam CBS). The resultant peroxide vulcanizate was denoted with SN, while the sulfur vulcanizate with SS.

The following fillers were used: ATT (Bentonit SWDC) from BDC Poland (Fig. 1a), silica (Aerosil 380) with a specific surface of $380 \mathrm{~m}^{2} \mathrm{~g}^{-1}$ from Evonik Degussa (Fig. 1c) and carbon nanofiber (Pr-25-XT-PS) from Pyrograf (Fig. 1d). These were added to cross-linked rubbers in a quantity of $8 \mathrm{phr}$, while their blends were added to the polymeric matrix in proportion 1:1.

To improve the miscibility of ATT with the rubber, i.e., to decrease its hydrophilicity, the filler was modified with the use of 3-aminopropylotrietoxysilane (Unisil Poland) (Fig. 1b). The modification of ATT consisted of mixing it with an aqueous solution of the silane (1:1) at a temperature of $55{ }^{\circ} \mathrm{C}$ for $2 \mathrm{~h}$, followed by drying to a constant weight.

\section{Methods}

The SEM images of fillers were taken by means of a SEM Quanta 250 FEG microscope (Fig. 1).
Elastomeric blends were prepared at room temperature with the use of a laboratory rolling mill $(D=150 \mathrm{~mm}$, $L=300 \mathrm{~mm}$ ). The rotational speed of the front roll was $20 \mathrm{rpm}$, friction 1.1 .

The blends were vulcanized in steel molds placed between electrically heated press shelves. The optimal vulcanization time $\left(\tau_{0.9}\right)$ at a temperature of $160{ }^{\circ} \mathrm{C}$ was determined by means of a WG-2 vulcameter according to PN-ISO 3417:1994.

The thermal properties of the vulcanizate obtained were tested under air within the temperature range of $25-800{ }^{\circ} \mathrm{C}$ by means of a MOM derivatograph (Budapest), using $\mathrm{Al}_{2} \mathrm{O}_{3}$ as a reference substance. Weighed portions were $90 \mathrm{mg}$ each, heating rate $7.9^{\circ} \mathrm{C} \mathrm{min}^{-1}$, and the sensitivities of thermal curves were as follow: TG $=100, \mathrm{DTA}=1 / 5, \mathrm{DTG}=1 / 30$.

The flammability of vulcanizates was determined by the oxygen index (OI) method, according to ISO 4589 using an apparatus from Fire Testing Technology Ltd and $50 \times 10 \times$ $4 \mathrm{~mm}$ specimens. The value of the OI is defined as the minimal oxygen concentration $\left[\mathrm{O}_{2}\right]$ in the oxygen/nitrogen mixture $\left[\mathrm{O}_{2} / \mathrm{N}_{2}\right]$ that either maintains flame combustion of the material for $3 \mathrm{~min}$ or consumes a length of $5 \mathrm{~cm}$ of the sample, with the sample placed in a vertical position (the top of the test sample is inflamed with a burner).
Fig. 1 SEM images. a ATT, b ATT modified with the use of silane, c silica Aerosil 380, and $\mathbf{d}$ carbon nanofiber PR-25-XT-PS
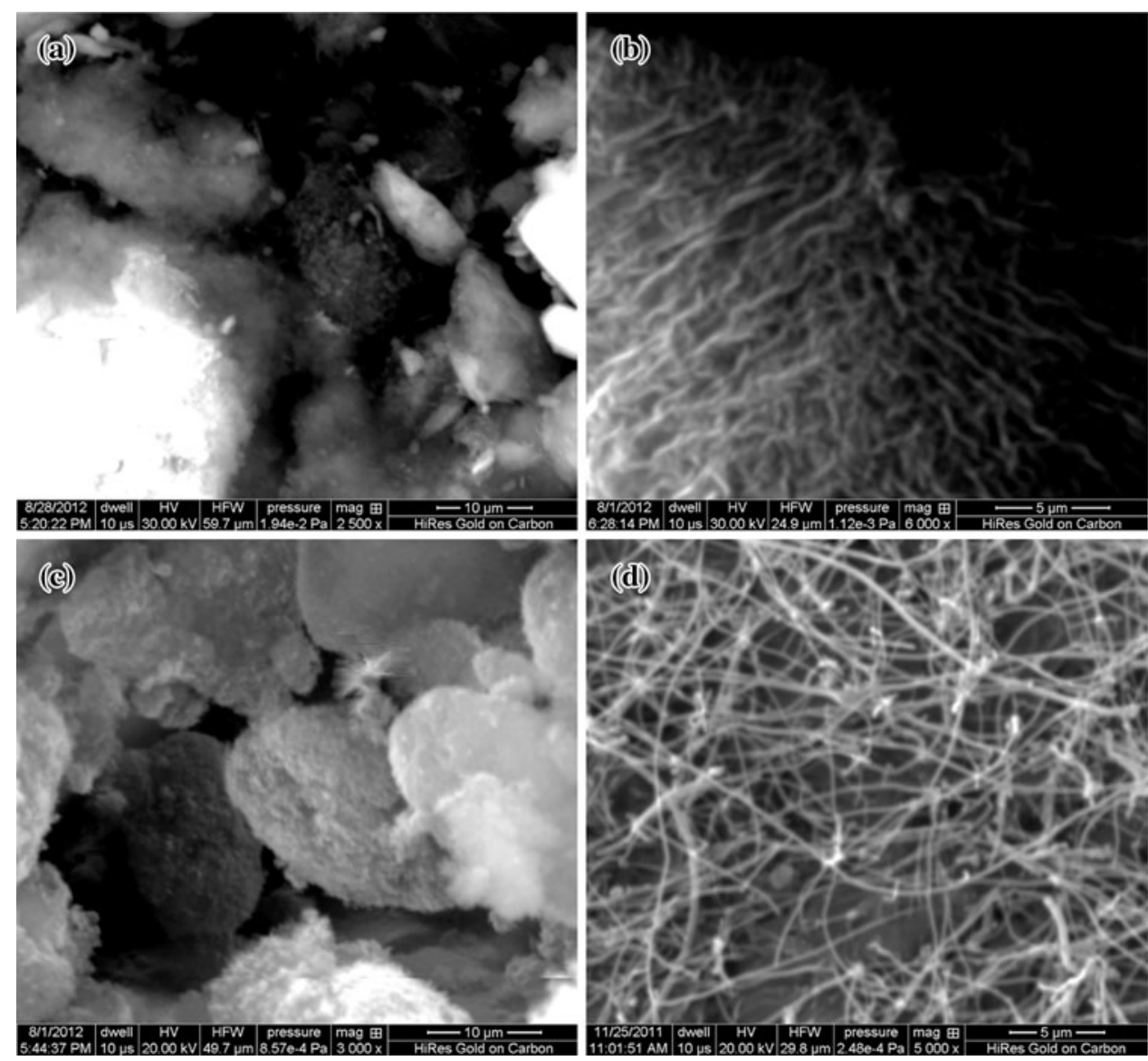
With a constant nitrogen flow rate through a measurement column $(\varnothing=75 \mathrm{~mm})$, amounting to $(40 \pm 2)$ $\mathrm{mm} \times \mathrm{s}^{-1}$, the oxygen concentration was selected so that the sample was completely burned within time $t=180 \mathrm{~s}$ $[2,3,11]$. The sample top was ignited for $5 \mathrm{~s}$ by means of a gas burner supplied with LPG.

We also tested flammability in air using identical samples as in the case of OI method. A sample in a vertical position was ignited with a gaseous burner for $5 \mathrm{~s}$ and its combustion time $\left(t_{\mathrm{s}}\right)$ was measured.

The vulcanizates under investigation were examined by the FAA micro-calorimeter from Fire Testing Technology Limited, with constant flow ratio oxygen to nitrogen amounting 1:4. The temperature of pyrolyser was $750{ }^{\circ} \mathrm{C}$, while that of combustor $900{ }^{\circ} \mathrm{C}$. During measurement the following parameters were recorded: ignition temperature, maximal heat emission rate, temperature of maximal heat emission rate, total heat emitted, heat capacity, and percentage oxygen consumption.

Flammability of vulcanizates under conditions of real fire was tested with the use of a cone calorimeter from Fire Testing Technology Limited. Elastomer samples with dimensions $(100 \times 100 \pm 1) \mathrm{mm}$ and a thickness of $(20 \pm 0.5) \mathrm{mm}$ were tested in a horizontal position, with a density of heat radiation flux amounting to $35 \mathrm{~kW} \mathrm{~m}^{-2}$.

During tests, the following parameters were recorded: initial sample weight, time to ignition, sample weight during testing, total heat released, effective combustion heat, average weight loss rate, sample final weight, time to extinction, and test duration.

The structure of the rubber combustion residue analyzed by means of a cone calorimeter was assessed on the basis of photographs and SEM images taken under a microscope equipped with the recording software Motic Images Plus, and electronic microscope Quanta 250 FEQ.

The use of SEM equipped with the detector of X-ray dispersion energy (EDS EDAX Genesis XM 4i (USA)) made it possible to obtain in a single stage of analysis information about the chemical composition and concentration of particular elements in the combustion residues.

The tensile strength of the vulcanizates tested was determined by means of a Zwick apparatus, model 1435, linked to a computer with appropriate software, according to standard PN-ISO 37:1998. The test samples used consisted of dumbbells, whose measurement section had a width of $4 \mathrm{~mm}$ and a thickness of about $1 \mathrm{~mm}$.

\section{Results and discussion}

From the literature review and the test results obtained it follows that ATT undergoes a clear four-stage decomposition within the temperature range $\Delta T=25-800{ }^{\circ} \mathrm{C}$
(Fig. 2). The first stage of mass loss amounting to $12.23 \%$, recorded at a temperature below $130{ }^{\circ} \mathrm{C}$ is connected with the release of water physically occluded between the fibrous crystals and some water physically combined with the crystal surface (so-called zeolitic water). The second stage of mass loss at $\Delta T_{2}=130-230{ }^{\circ} \mathrm{C}$, amounting to $2.2 \%$ consists of releasing the remaining portion of zeolitic water. The third stage of mass loss at $\Delta T_{3}=230-730{ }^{\circ} \mathrm{C}$, amounting to $11.2 \%$ is due to the removal of water chemically combined with aluminosilicate (hydroxyl groups of water combined with the surface of ATT). At a temperature above $730{ }^{\circ} \mathrm{C}$ the remaining portion of water chemically combined with ATT is released and the organic substances adsorbed on the ATT surface are burned [12, 13].

The modification of ATT with silane to reduce its hydrophilicity partly uncovers its fibrous structure, making no significant difference in the course of TG and DTG curves (Figs. 2, 3).

The first step of the thermal decomposition of ATT modified with silane occurs at $\Delta T_{1}=80-150{ }^{\circ} \mathrm{C}$ and is accompanied by a weight loss of $4.5 \%$, which corresponds to the release of water physically combined with ATT. The second step occurring at $\Delta T_{2}=150-260{ }^{\circ} \mathrm{C}$, accompanied by a further mass loss of $2.3 \%$ is connected with the loss of the remaining zeolytic water combined with ATT.

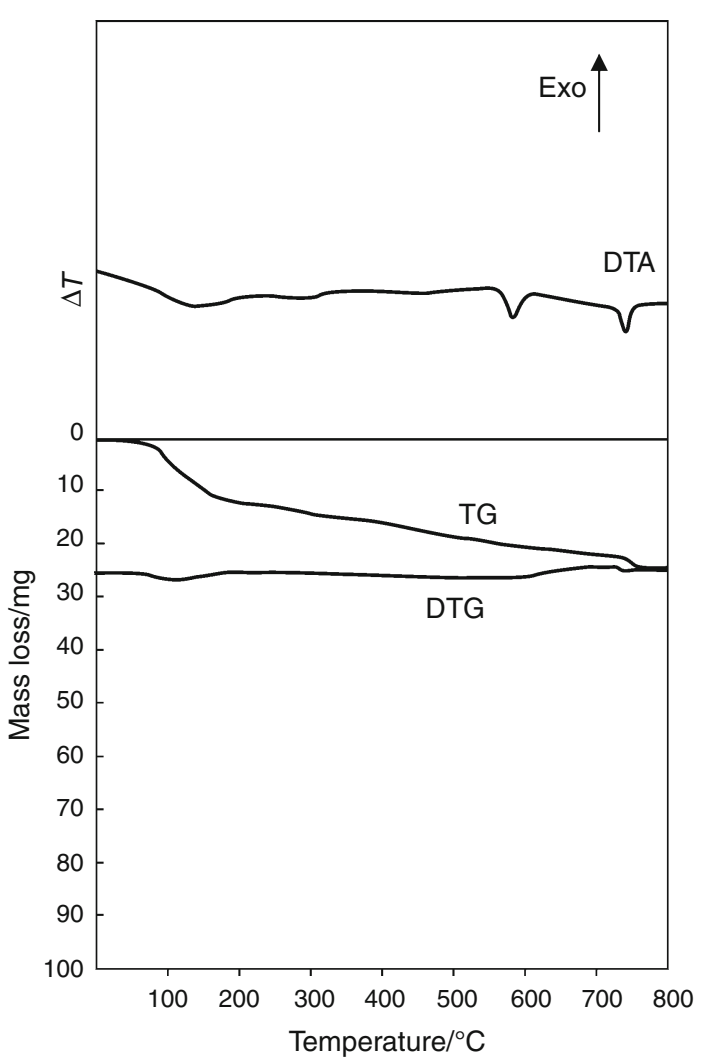

Fig. 2 Thermal analysis of ATT 


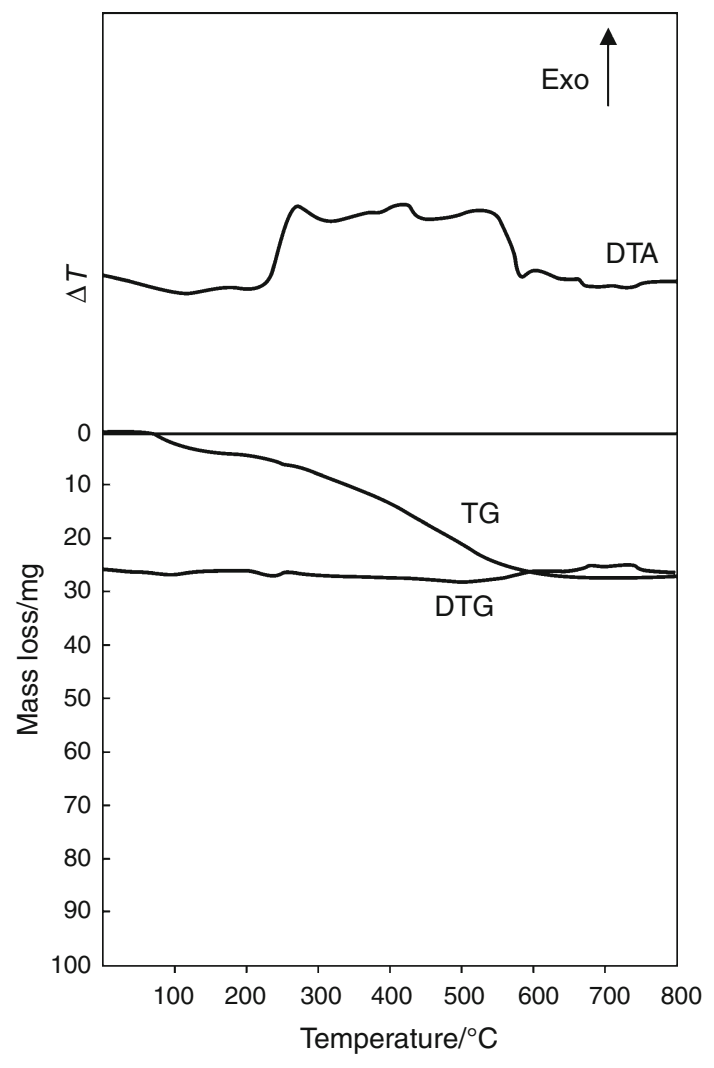

Fig. 3 Thermal analysis of ATT modified with the use of silane
At $\Delta T_{3}=260-580{ }^{\circ} \mathrm{C}$ both the water chemically combined with ATT and a small quantity of the modifier uncombined with the ATT surface are released (Fig. 3).

From the comparative analysis of the test results listed in Table 1 it clearly follows that the thermal stability of the peroxide vulcanizates of SBR, expressed by parameter $T_{5}$, is higher than that of sulfur vulcanizates as the energy of the crosswise $\mathrm{C}-\mathrm{C}$ bonds of the elastomer cross-linked with dicumyl peroxide is considerably higher than that of the sulfide bridges formed during cross-linking with sulfur.

The fillers used ambiguously influence the thermal stability of the composites investigated, determined with parameters $T_{5}$ and $T_{50}$. In the case of peroxide vulcanizates, unmodified ATT itself and that mixed with carbon nanofiber (ATT-CNF) or with silica (ATT-Si) considerably increases the value of parameter $T_{5}$. A significant improvement in the thermal stability of sulfur vulcanizates determined with parameter $T_{5}$ occurs under the influence of the ATT modified with silane.

Regardless of the spatial network structure the fillers used bring about a significant reduction in the thermal decomposition rate $(\mathrm{d} m / \mathrm{d} t)$ of the vulcanizates investigated (Table 1). These also decrease the sample mass loss rate (MLR) during their combustion (Figs. 5, 6). The considerable reduction in the thermal decomposition rate of the vulcanizates investigated in relation to unfilled samples ( $\mathrm{SN}, \mathrm{SS})$ is due to the decreased segmental mobility of

Table 1 Thermal analysis of vulcanizates

\begin{tabular}{|c|c|c|c|c|c|c|c|}
\hline Sample $^{\mathrm{a}}$ & $T_{5} /{ }^{\circ} \mathrm{C}$ & $T_{50} /{ }^{\circ} \mathrm{C}$ & $\mathrm{d} m / \mathrm{d} t / \mathrm{mm}$ & $T_{\mathrm{RMAX}} /{ }^{\circ} \mathrm{C}$ & $\mathrm{Pw} / \%$ & $T_{\mathrm{s}} /{ }^{\circ} \mathrm{C}$ & $P_{800} / \%$ \\
\hline $\mathrm{SN}$ & 350 & 419 & 80 & 415 & 19 & 475 & 5 \\
\hline $\mathrm{SN}-\mathrm{ATT}$ & 365 & 405 & 56 & 410 & 22.2 & 480 & 11.1 \\
\hline SN-ATTM & 305 & 405 & 52 & 400 & 22.2 & 480 & 11.1 \\
\hline SN-ATT-CNF & 360 & 410 & 45 & 405 & 30 & 480 & 14.4 \\
\hline $\mathrm{SN}-\mathrm{Si}$ & 360 & 405 & 52 & 390 & 22.2 & 480 & 11.1 \\
\hline $\mathrm{SN}-\mathrm{ATT}-\mathrm{Si}$ & 365 & 410 & 53 & 405 & 28.8 & 480 & 17.7 \\
\hline SS & 300 & 400 & 70 & 365 & 20 & 490 & 8.8 \\
\hline SS-ATT & 305 & 405 & 43 & 390 & 36.6 & 475 & 13.3 \\
\hline SS-ATTM & 330 & 410 & 42 & 390 & 28.8 & 480 & 13.3 \\
\hline SS-ATT-CNF & 260 & 405 & 35 & 390 & 28.8 & 480 & 10 \\
\hline $\mathrm{SS}-\mathrm{Si}$ & 270 & 400 & 55 & 400 & 23.3 & 480 & 10 \\
\hline SS-ATT-Si & 310 & 405 & 37 & 390 & 30 & 480 & 17.7 \\
\hline
\end{tabular}

$S N$ peroxide vulcanizate of SBR, $S S$ sulfur vulcanizate of SBR, $S N-A T T$ peroxide vulcanizate containing ATT, $S N-A T T M$ peroxide vulcanizate containing ATT modified with the use of silane, $S N-A T T-C N F$ peroxide vulcanizate containing ATT and carbon nanofiber, $S N-S i$ peroxide vulcanizate containing silica, $S N-A T T-S i$ peroxide vulcanizate containing ATT and silica, $S S-A T T$ sulfur vulcanizate containing ATT, $S S-A T T M$ sulfur vulcanizate containing ATT modified with the use of silane, $S S-A T T-C N F$ sulfur vulcanizate containing ATT and carbon nanofiber, $S S-S i$ sulfur vulcanizate containing silica, $S S-A T T-S i$ sulfur vulcanizate containing ATT and silica, $T_{5}$ and $T_{50}$ temperature of sample 5 and $50 \%$ mass loss, respectively, $\mathrm{d} m \times \mathrm{d} t^{-1}$ maximum rate of thermal decomposition of vulcanizates, $T_{\mathrm{RMAX}}$ temperature of maximum rate of thermal decomposition of vulcanizates, $P w$ residue after the thermal decomposition of vulcanizates, $T_{\mathrm{s}}$ temperature of residue burning after the thermal decomposition of vulcanizates, $P_{800}$ residue after heating up to $T=800{ }^{\circ} \mathrm{C}$

${ }^{a}$ Each of the filler were added to cross-linked rubber in a quantity of $8 \mathrm{phr}$. Blends of the fillers were added to the polymeric matrix in proportion $1: 1$ 

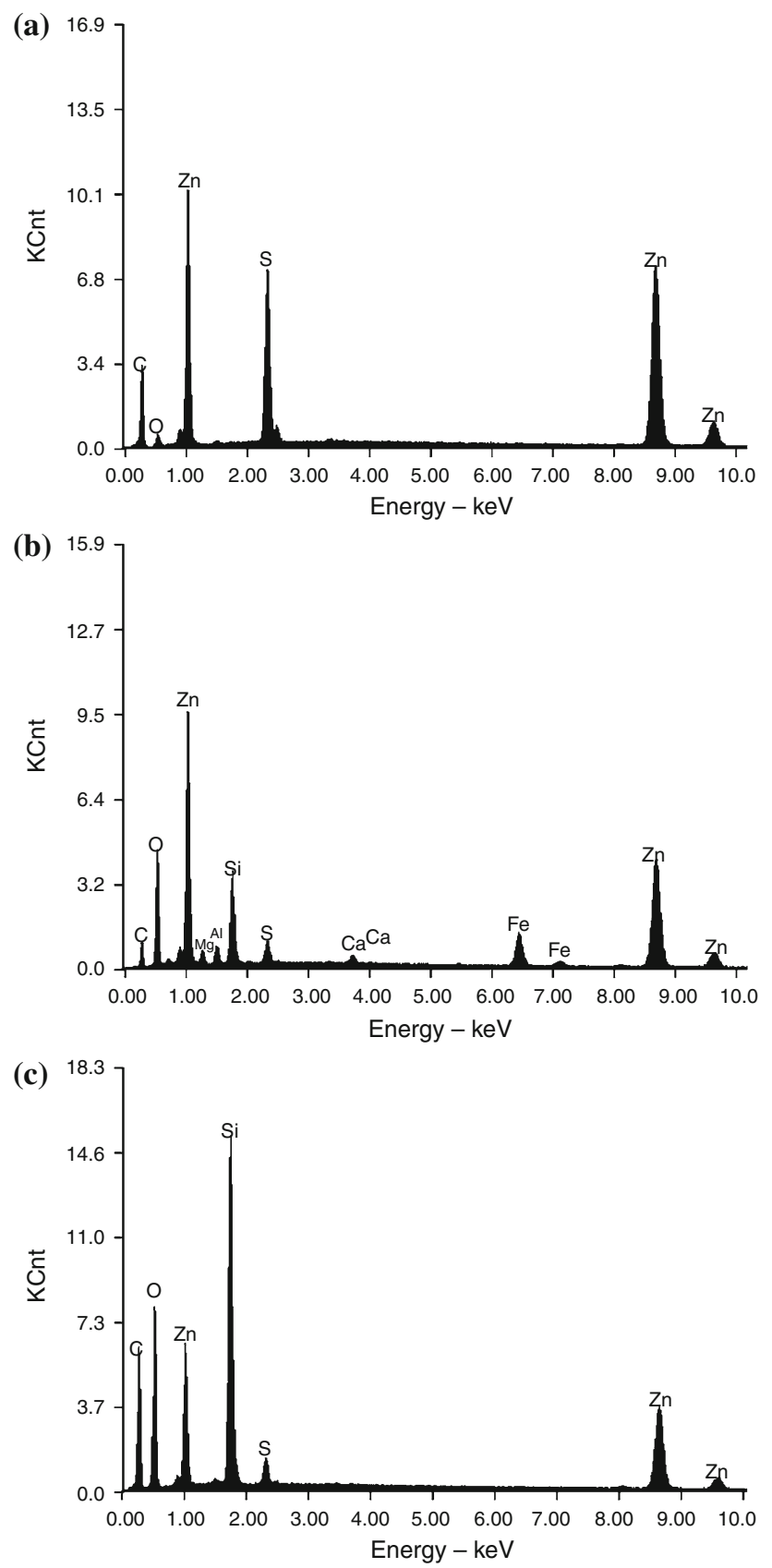

Fig. 4 EDS analysis residue after burning. a Sulfur vulcanizate SS $\left(\mathrm{C}=27.51 \%, \mathrm{O}_{2}=2.58, \mathrm{~S}=7.16, \mathrm{Zn}=62.75 \%\right)$, b sulfur vulcanizate containing SS-ATT $\left(\mathrm{C}=18.09 \%, \mathrm{O}_{2}=21.93 \%, \mathrm{Mg}=\right.$ $2.52 \%, \mathrm{Al}=2.25 \%, \mathrm{Si}=9.84 \%, \mathrm{~S}=1.84 \%, \mathrm{Ca}=0.61 \%$, $\mathrm{Fe}=5.1 \%, \mathrm{Zn}=37.82 \%$ ), c sulfur vulcanizate containing silica $\mathrm{SS}-\mathrm{Si}\left(\mathrm{C}=44.52 \%, \mathrm{O}_{2}=27.55 \%, \mathrm{Si}=12.81 \% \mathrm{~S}=0.93 \%, \mathrm{Zn}=\right.$ $14.19 \%)$

elastomer chains around the filler particles. The decreased segmental mobility reduces the amplitude of thermal vibrations and consequently inhibits degradation and destruction processes.

The higher values of parameter $\mathrm{d} m / \mathrm{d} t$ (Table 1 ) and MLR (Fig. 6) of the composites containing ATT compared

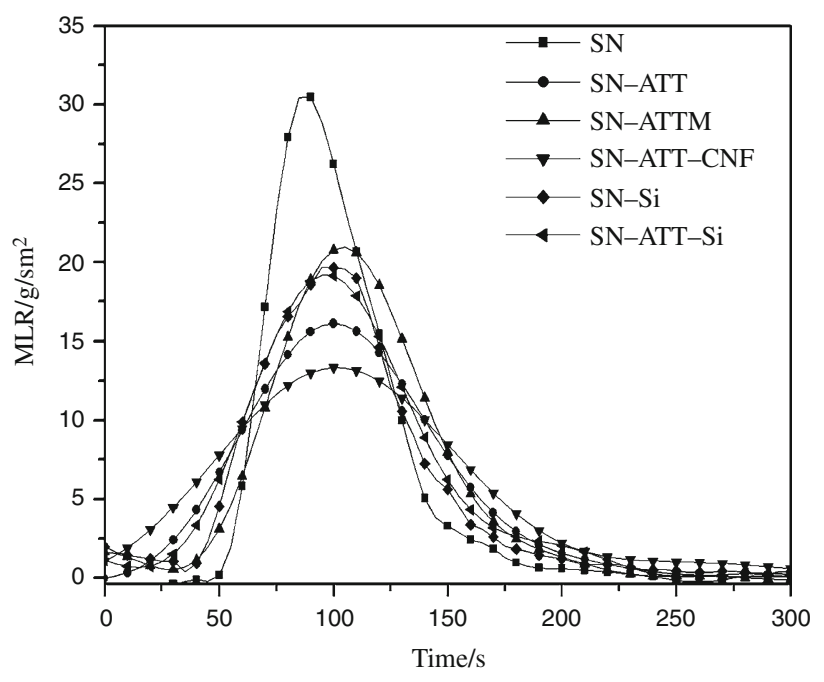

Fig. 5 MLR curves of peroxide vulcanizates of SBR rubber

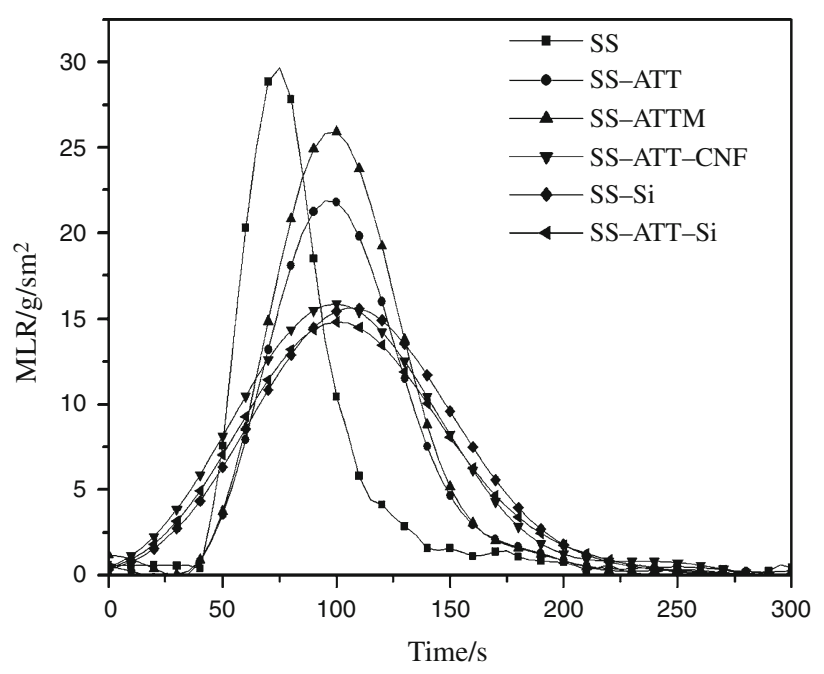

Fig. 6 MLR curves of sulfur vulcanizates of SBR rubber

to those of the vulcanizates containing silica are probably connected with the presence of metal oxides, resulted from the thermal decomposition of ATT. The metal oxides present on the surface of the composite boundary layer increase the activity of hydrocarbon radicals resulted from the polymer thermal decomposition in consequent thermal processes [10].

The elementary analysis of the combustion residue of ATT-containing composite showed the contents of $\mathrm{Mg}$, $\mathrm{Al}, \mathrm{Ca}$, and $\mathrm{Fe}$ amounting to $2.52,2.25,0.61$, and $5.1 \%$, respectively (Fig. 4b).

Considerably lower values of the parameters $\mathrm{d} m / \mathrm{d} t$ and MLR (Table 1; Figs. 5, 6) of vulcanizates filled with carbon nanofibers and ATT compared to those of the remaining composites result from the fact that carbon nanofiber as carbon black can be a scavenger of radicals. Thus, its presence inhibits free-radical reactions increasing 

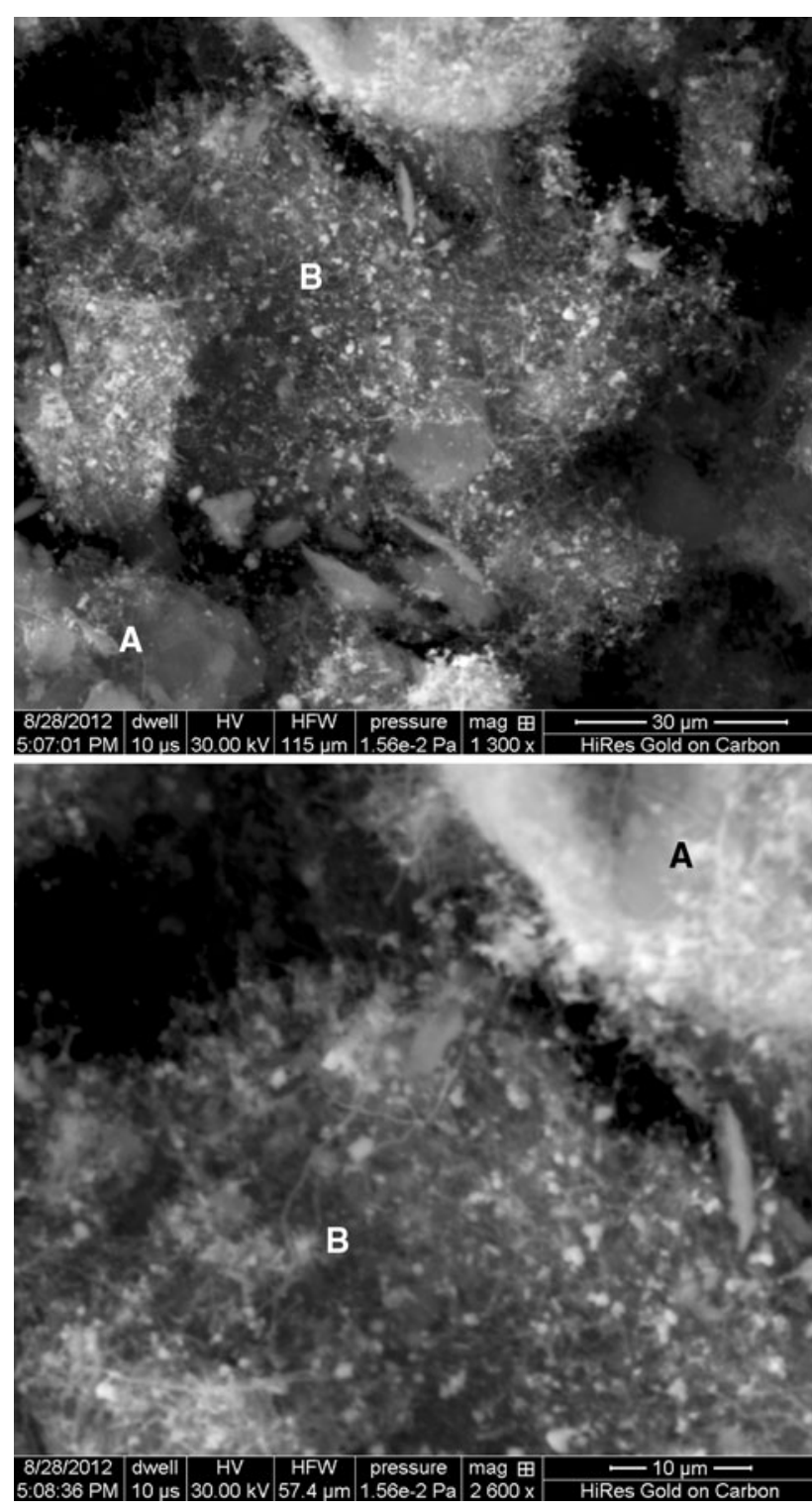

Fig. 7 SEM images of residue after burning SS-ATT-CNF vulcanizate. $A$ ATT needles and $B$ carbon nanofibers

at the same time the probability of the primary macroradical recombination through increasing their dwell time in the cage [14-16].

One of the basic parameters of the thermal stability of polymers and polymeric materials is the residue from thermal decomposition $(\mathrm{Pw})$. It exerts a significant effect on the flammability of polymeric composites. An increase in the value of this parameter makes the amount of flammable and non-flammable destruction products passing to flame be lower. The presence of both silane-modified ATT and unmodified ATT or silica influences the value of Pw to the same extent. The EDS analyses of the residues from the combustion of unfilled composites and those containing ATT or silica showed that ATT, unlike silica, did not initiate carbonization processes (Fig. $4 \mathrm{a}-\mathrm{c}$ ).
The considerable increase in the content of carbon in the combustion residue of the vulcanizate containing silica, in relation to the unfilled one, facilitates the formation of a thermally stable boundary layer hindering the flow of mass and energy between flame and solid phase. It was found that in the case of the peroxide vulcanizates of SBR, the highest values of $\mathrm{Pw}$ were shown by the composites containing both carbon nanofiber and ATT (SN-ATT-CNF). From the investigations carried out so far it follows that an increase in the content of carbon nanofiber in polymer is accompanied by a decrease in the value of parameter $\mathrm{Pw}$ in relation to unfiled samples. There are also decreases in the temperature of maximum combustion rate of the residue from the thermo-oxidative decomposition of vulcanizates filled with nanofibers [17]. Both carbon nanofibers and carbon black are completely burned above $\Delta T=$ $400-450{ }^{\circ} \mathrm{C}$. The SEM images of the combustion residue from the vulcanizates containing ATT and carbon nanofiber clearly show however the presence of both carbon nanofiber and crystalline ATT filaments (Fig. 7).

According to the literature data, the boundary layer temperature ranges from 420 to $520{ }^{\circ} \mathrm{C}$ depending on elastomer, while the flame temperature can reach 950-1000 ${ }^{\circ} \mathrm{C}[14,18]$. Thus, one can assume that ATT is characterized by good isolating properties hindering the combustion of carbon nanofiber contained in the sample.

The increase in the thermal stability of the elastomer investigated under the influence of the fillers incorporated is accompanied by the reduction in its flammability $\left(\mathrm{OI}, t_{\mathrm{s}}\right.$, $T_{\mathrm{z}}$, and $\mathrm{HRR}_{\max }$; Table 2; Figs. 8, 9), as confirmed by both the decreased thermo-oxidative decomposition rate of SBR $(\mathrm{d} m / \mathrm{d} t)$ and increased residue from this process. The analysis of results listed in Table 2 leads to a conclusion that vulcanizates containing modified ATT or silica are characterized by comparable values of OI. The lower flammability of composites containing ATT compared to unfilled vulcanizate results, first of all, from the isolating properties of ATT that protects the polymer against consequent reactions of degradation and thermal destruction, especially in the initial stage of combustion. In the subsequent stage of combustion (flame combustion), the flame-retardant effect of ATT is decreased as the so-called aluminosilicate islets are formed in the boundary layer (Fig. 10a) that do not constitute any barrier for mass and energy transfer to flame, as well as oxygen diffusion inside the sample (Tables 2; Figs. 10a, 11, 12).

On the other hand, barrier properties play a significant role in reducing composite flammability by decreasing the transport rate of volatile and flammable destruction products to the flame zone (Fig. 10b). In the presence of silica, cavitation and carbonization processes in the solid phase of the sample under combustion proceed to a larger extent (Fig. 4). Its great heat capacity is also of importance (Table 2). Silica has the 
Table 2 Flammability test of vulcanizates

\begin{tabular}{llllllll}
\hline Sample & $\mathrm{OI}$ & $t_{\mathrm{s}} / \mathrm{s}$ & $T_{\mathrm{z}}{ }^{\circ} \mathrm{C}$ & $\mathrm{HRR}_{\max } / \mathrm{W} \mathrm{g} \mathrm{g}^{-1}$ & Total HR/kJ g$^{-1}$ & HR capacity/J/g K & Oxygen consumption/ \% \\
\hline SN & 0.210 & 194 & 350 & 450 & 34.5 & 501 & 40.11 \\
SN-ATT & 0.229 & 347 & 375 & 390 & 34.4 & 426 & 81.17 \\
SN-ATTM & 0.233 & 218 & 362 & 376 & 34.3 & 388 & 63.91 \\
SN-ATT-CNF & 0.245 & 363 & 374 & 348 & 30.2 & 395 & 56.92 \\
SN-Si & 0.234 & 332 & 366 & 397 & 33.4 & 517 & 38.72 \\
SN-ATT-Si & 0.240 & 319 & 377 & 315 & 30.3 & 417 & 30.32 \\
SS & 0.220 & 273 & 355 & 399 & 34.3 & 397 & 44.91 \\
SS-ATT & 0.235 & 316 & 370 & 371 & 32.2 & 367 & 46.90 \\
SS-ATTM & 0.238 & 298 & 360 & 375 & 33.4 & 369 & 45.09 \\
SS-ATT-CNF & 0.255 & 360 & 373 & 310 & 30.9 & 334 & 40.20 \\
SS-Si & 0.240 & 332 & 367 & 341 & 29.3 & 320 & 34.57 \\
SS-ATT-Si & 0.250 & 302 & 376 & 290 & 29.9 & 29.37
\end{tabular}

OI: oxygen index, $t_{\mathrm{s}}$ : combustion time in air, $T_{\mathrm{z}}$ : ignition temperature, $\mathrm{HRR}_{\max }$ : maximal heat release rate, total HR: total heat release, $\mathrm{HR}$ : heat release

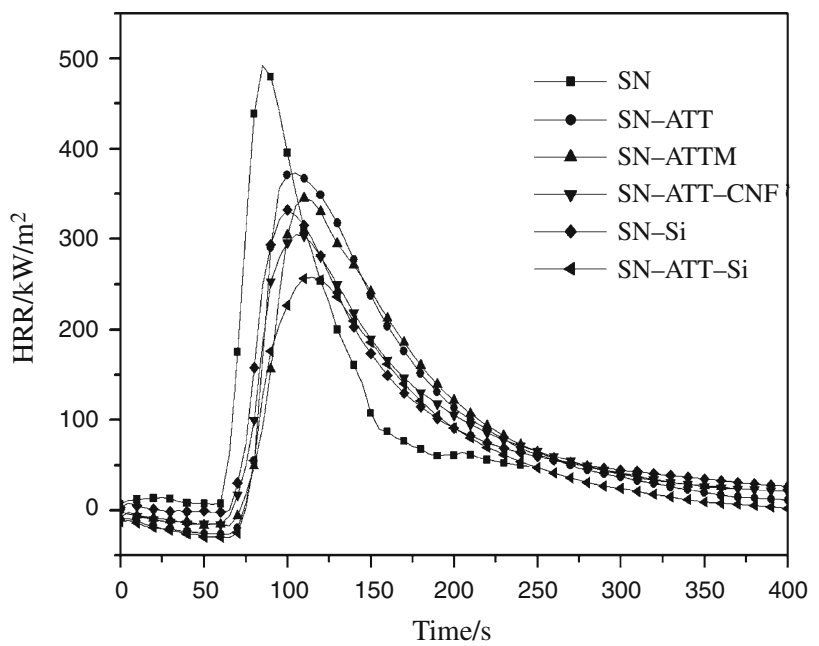

Fig. 8 HRR curves of peroxide vulcanizates of SBR rubber

capability to trap free radicals resulting from the thermal degradation and destruction of polymer. However, according to Kashiwagi, the decreased flammability of polymer/silica composites is connected to a considerably larger extent with physical processes proceeding in the condensed phase than chemical reactions in the gaseous phase [19]. Of paramount importance is the equilibrium between the filler density and specific surface and the viscosity of the molten polymer. It depends on the equilibrium whether silica will accumulate near the surface of the sample under combustion going into the composition of boundary layer or if it will be immersed in the polymer melt [19-22]. One should pay attention to the increase in oxygen content in the residues from burned composites filled with ATT or silica compared to that of unfilled vulcanizates (Fig. $4 \mathrm{a}-\mathrm{c}$ ). It points to intensive chemisorption processes, i.e., strongly exothermic oxidative reactions

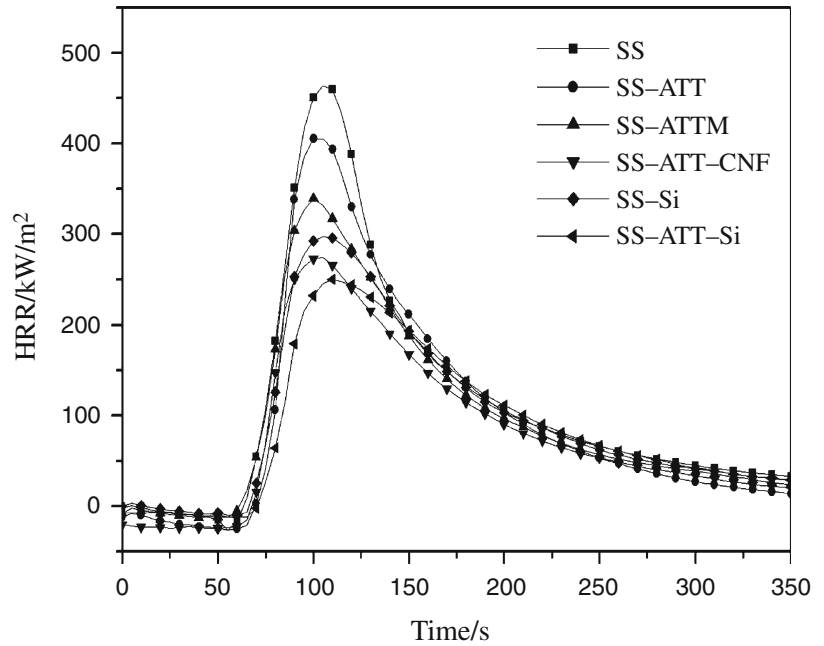

Fig. 9 HRR curves of sulfur vulcanizates of SBR rubber

between the solid phase of the sample under combustion and gaseous phase.

The considerable reduction in the flammability of vulcanizates containing both silica and ATT, compared to that of the composite filled only with silica, determined by OI and $T_{\mathrm{z}}$ (Table 2; Fig. 8,9) is connected with the increase in the homogeneity of the residue from the combustion of SN-ATT-Si and SS-ATT-Si vulcanizates (Fig. 10b, c).

Thus, one should assume that the synergic action of ATT and silica considerably influences the formation of a homogeneous insulating boundary layer during the combustion of composite containing these fillers. SBR vulcanizates filled with silica and ATT, regardless of the elastomer spatial network, are also characterized by the lowest values of the fire hazard parameters from among the elastomeric materials investigated $\left(\mathrm{HRR}_{\max }\right.$, Total HR; 
Fig. 10 Images of residues from combustion vulcanizates. a SS-ATT, b SS-Si, c SSATT-Si, and d SS-ATT-CNF
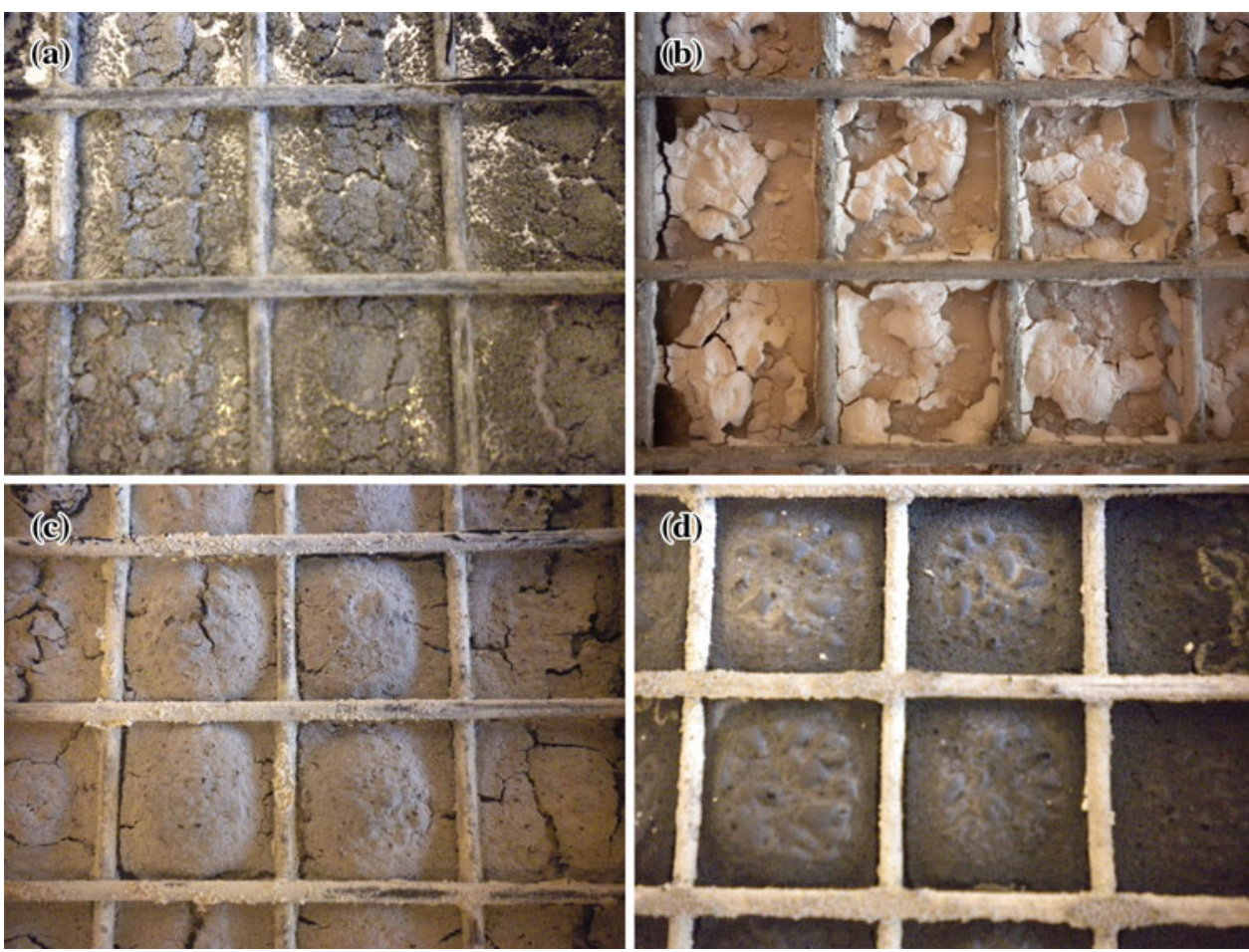

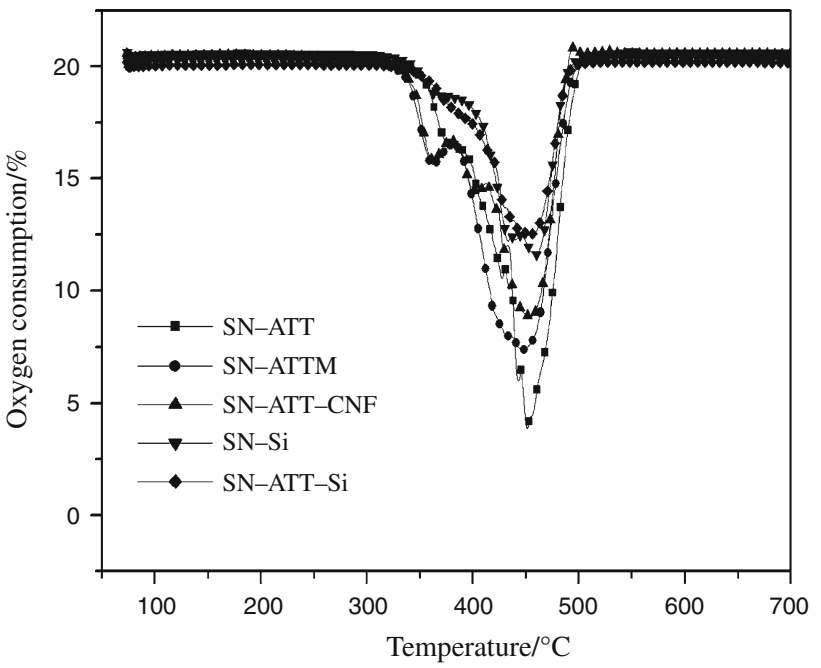

Fig. 11 Oxygen consumption during combustion peroxide vulcanizates of SBR rubber

Table 2). During their combustion, one can observe the lowest consumption of oxygen (Table 2; Figs. 11, 12).

From the comparative analysis of parameters listed in Table 2 it follows that the flammability of vulcanizates containing carbon nanofiber and ATT is the lowest from among the material investigated, as confirmed by the values of OI, $t_{\mathrm{s}}$, $T_{\mathrm{z}}$. Carbon nanofiber is characterized by a large specific surface amounting to $65-75 \mathrm{~m}^{2} \mathrm{~g}^{-1}$. Thus, it fulfills the function of sorbent of gaseous products of the elastomer thermal decomposition passing to the combustion zone as well as the

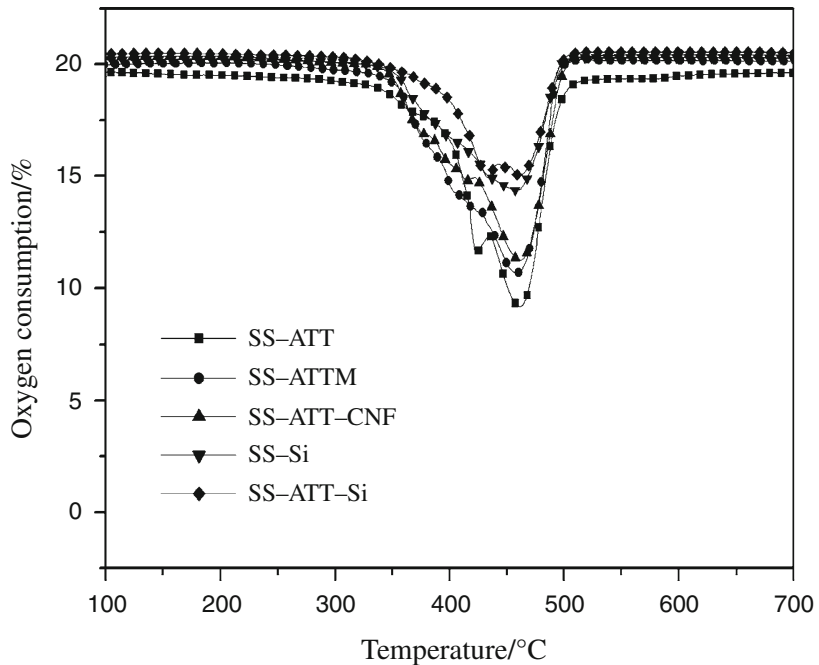

Fig. 12 Oxygen consumption during combustion sulfur vulcanizates of SBR rubber

function of free radical scavenger mentioned above. It is not an unimportant fact that during thermal decomposition resulting from the combustion of a sample containing carbon nanofiber and ATT, there is a uniform boundary layer formed with no visible cracks, as confirmed by the homogeneous structure of the combustion residue (Fig. 10d), which effectively reduces the mass and energy transport during the combustion of polymeric material.

In this connection, the presence of carbon nanofiber reduces the thermal decomposition rate of the composite 
Table 3 Mechanical properties of composites

\begin{tabular}{llllll}
\hline Sample & \multicolumn{2}{l}{ Stress/MPa } & $T_{\mathrm{s}} / \mathrm{MPa}$ & $E_{\mathrm{b}} / \%$ \\
\cline { 2 - 4 } & $100 / \%$ & $200 / \%$ & $300 / \%$ & & \\
\hline SN & 0.7 & 0.94 & 1.23 & 1.80 & 580 \\
SN-ATT & 0.85 & 1.21 & 1.57 & 2.12 & 428 \\
SN-ATTM & 0.93 & 1.19 & 1.67 & 2.15 & 430 \\
SN-ATT-CNF & 1.37 & 1.92 & 2.30 & 4.26 & 691 \\
SN-Si & 1.15 & 1.79 & 2.58 & 5.16 & 483 \\
SN-ATT-Si & 1.11 & 1.53 & 1.94 & 4.41 & 622 \\
SS & 1.02 & 1.54 & 2.02 & 2.37 & 363 \\
SS-ATT & 1.48 & 2.12 & 2.65 & 2.93 & 345 \\
SS-ATTM & 1.60 & 2.28 & 3.10 & 3.01 & 340 \\
SS-ATT-CNF & 3.03 & 4.66 & 5.79 & 5.95 & 297 \\
SS-Si & 1.24 & 1.80 & 2.49 & 3.29 & 385 \\
SS-ATT-Si & 1.61 & 2.39 & 3.17 & 5.20 & 445 \\
\hline
\end{tabular}

$T_{\mathrm{s}}$ tension strength, $E_{\mathrm{b}}$ Elongation at break

filled with carbon nanofiber and ATT (Figs. 5,6) as well as limits the fire hazard defined by the maximum heat release rate $\left(\mathrm{HRR}_{\max }\right)$ and the oxygen consumption during its combustion (Table 2; Figs. 8, 9, 11, 12). From the results of our previous investigation it follows that the boundary layers of vulcanizated filled with carbon nanofiber have a honeycomb structure [17]. The addition of ATT to carbon nanofiber, as in the case of silica, increases the homogeneity of boundary layers.

From the point of view of the functional properties of polymeric materials a great role is played by their mechanical properties (Table 3). Regardless of the filler used, under the influence of its action the mechanical parameters of vulcanizates are improved. A high tensile strength, $T_{\mathrm{s}}$, is shown by SBR vulcanizates filled with ATT and carbon nanofiber or ATT and silica. As expected, the vulcanizates containing only silica also show a considerable tensile strength.

\section{Conclusions}

Our findings have shown that ATT is active filler improving the thermal and mechanical properties of crosslinked SBR as well as reducing the flammability and fire hazard of the vulcanizates of this elastomer.

The fillers used increase the thermal stability of the cross-linked SBR defined by the rate of its thermo-oxidative decomposition and the residue from that process, which exerts a significant effect on reducing the flammability of the elastomeric material obtained.

A considerable increase in the resistance of cross-linked SBR and its reduced fire hazard result to a large extent from the structure of the boundary layer formed during the combustion of polymeric materials. ATT and its mixtures with carbon nanofiber or silica also improve the mechanical parameters of the vulcanizate investigated.

Open Access This article is distributed under the terms of the Creative Commons Attribution License which permits any use, distribution, and reproduction in any medium, provided the original author(s) and the source are credited.

\section{References}

1. Janowska G, Kucharska-Jastrząbek A, Rybiński P. Thermal stability, flammability and fire hazard of butadiene-acrylonitrile rubber nanocomposites. J Therm Anal Calorim. 2011;103:1039-46.

2. Rybiński P, Janowska G, Jóźwiak M, Pająk A. Thermal properties and flammability of nanocomposites based on diene rubbers and naturally occurring and activated halloysite nanotubes. J Therm Anal Calorim. 2012;107:1243-9.

3. Rybiński P, Janowska G, Jóźwiak M, Pająk A. Thermal stability and flammability of butadiene-styrene rubber nanocomposites. J Therm Anal Calorim. 2012;109(2):561-71.

4. Tian M, Qu Ch, Feng Y, Zhang L. Structure and properties of fibrillar silicate/SBR composites by direct blend process. J. Mater. Sci. 2003;38:4917-24.

5. Bradley WF. The structural scheme of attapulgite. Am Mineral. 1940;24:405-10.

6. Sun L-H, Yang Z-G, Li X-H. Effects of the treatment of attapulgite and filler contents on tensile properties of PTFE and attapulgite reinforced fabric composites. Composites A. 2009;40: 1785-91.

7. Wang L, Sheng J. Preparation and properties of polypropylene/ org-attapulgite nanocomposites. Polymer. 2005;46:6243-9.

8. Cao E, Bryant R, Williams DJA. Electrochemical properties of Na-attapulgite. J Colloid Interface Sci. 1996;179:143-50.

9. Tian M, Liang W, Rao G, Zhang L, Guo C. Surface modification of fibrillar silicate and its reinforcing mechanism on FS/rubber composites. Compos Sci Technol. 2005;65:1129-38.

10. Yang F, Nelson GL. Combination effect of nanoparticles with flame retardants on the flammability of nanocomposites. Polym Degrad Stab. 2011;96:270-6.

11. Rybiński P, Janowska G, Kucharska-Jastrząbek A, Pająk A, Wójcik I, Wesołek D, Bujnowicz K. Flammability of vulcanizates of diene rubbers. J Therm Anal Calorim. 2012;107:1219-24.

12. Darvishi Z, Morsali A. Sonochemical preparation of palygorskite nanoparticles. Appl Clay Sci. 2011;51:51-3.

13. Cheng H, Yang J, Frost RL. Thermogravimetric analysis-mass spectrometry (TG-MS) selected Chinese palygorskites-implications for structural water. Thermochim Acta. 2011;512:202-7.

14. Janowska G. Thermal Stability and Flammability of Elastomers. Lodz: Scientific Books of Technical University of Lodz. Lodz Academic Press; 1998. p. 1-107.

15. Janowska G, Rybiński P. Influence of carbon black on thermal properties and flammability of cross-linked elastomers. J Therm Anal Calorim. 2008;91:697-701.

16. $\mathrm{Xu} \mathrm{H}, \mathrm{Li} \mathrm{B}, \mathrm{Wu}$ Ch. Polymer grafting onto carbon black by solid state method. Polym J. 2006;38(8):807-13.

17. Rybiński P, Janowska G. Thermal properties and flammability of nanocomposites based on nitrile rubbers and activated halloysite nanotubes and carbon nanofibers. Thermochim Acta. 2012;549: $6-12$.

18. Ślusarski L, Janowska G. Palność elastomerów. Polimery. 1982; 27:13-6. 
19. Kashiwagi T, Gilman JW, Butler KM, Harris RH, Shields JR, Asano A. Flame retardant mechanism of silica gel/silicas. Fire Mater. 2000;24:277-89.

20. Janowska G, Rybiński P, Jantas R. Effect of the modification of silica on thermal properties and flammability of cross-linked butadiene-acrylonitrile rubbers. J Therm Anal Calorim. 2007;87: $511-7$.
21. Rybiński P, Janowska G, Kucharska-Jastrząbek A. Influence of surface modification on thermal stability and flammability of cross-linked rubbers. J Therm Anal Calorim. 2010;100:1037-44.

22. Rybiński P, Janowska G, Ślusarski L. Influence of cryogenic modification of silica on thermal properties and flammability of cross-linked nitrile rubber. J Therm Anal Calorim. 2010;101: $665-70$. 